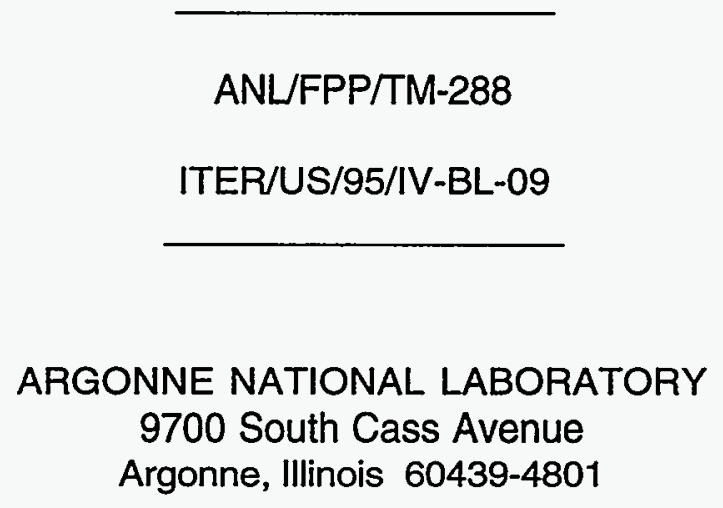

SUMMARY REPORT FOR ITER TASK - T68:

MHD FACILITY PREPARATION fOr LI/N BLANKET OPTION

\author{
by \\ Claude B. Reed, Robert C. Haglund, Martha E. Miller, \\ and James R. Nasiatka \\ Fusion Power Program/Technology Development Division/ \\ Igor R. Kirillov, Anatoli P. Ogorodnikov, \\ Guennadi V. Preslitski, and Guennadi P. Goloubovitch \\ MHD-Machines Laboratory \\ The D.V. Efremov Scientific Research \\ Institute of Electrophysical Apparatus \\ 189631 St. Petersburg, Russia
}

August 1995

Work supported by the

Office of Fusion Energy

U.S. Department of Energy

under Contract W-31-109-Eng-38 


\section{DISCLAIMER}

This report was prepared as an account of work sponsored by an agency of the United States Government. Neither the United States Government nor any agency thereof, nor any of their employees, make any warranty, express or implied, or assumes any legal liability or responsibility for the accuracy, completeness, or usefuiness of any information, apparatus, product, or process disclosed, or represents that its use would not infringe privately owned rights. Reference herein to any specific commercial product, process, or service by trade name, trademark, manufacturer, or otherwise does not necessarily constitute or imply its endorsement, recommendation, or favoring by the United States Government or any agency thereof. The views and opinions of authors expressed herein do not necessarily state or reflect those of the United States Government or any agency thereof. 


\section{DISCLAIMER}

Portions of this document may be illegible in electronic image products. Images are produced from the best available original document. 


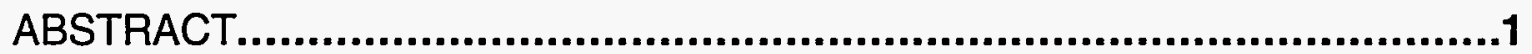

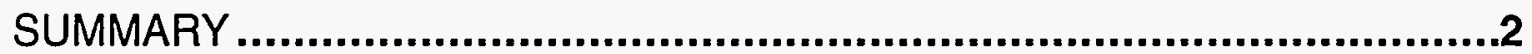

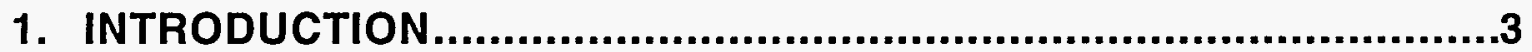

2. FUNCTIONS AND DESIGN REQUIREMENTS ...........................4

2.1 Functions....................................................................4

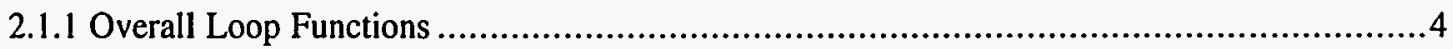

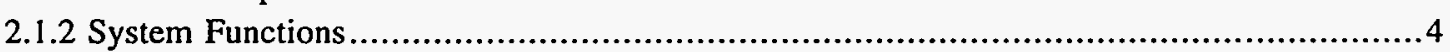

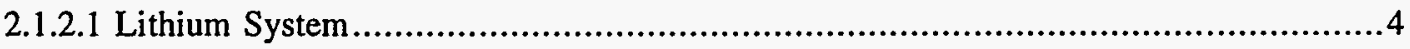

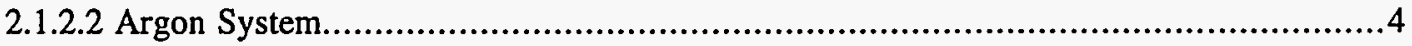

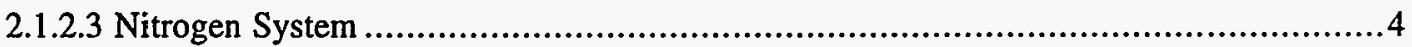

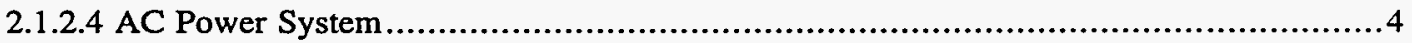

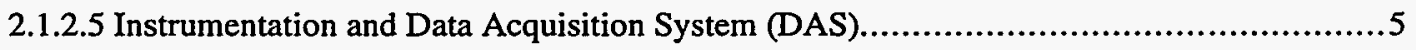

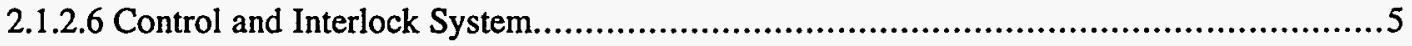

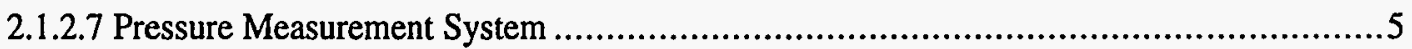

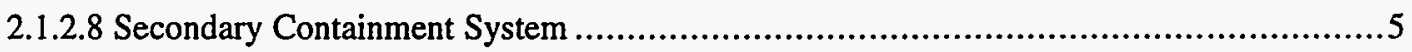

2.1.2.9 Leak Detection, Smoke Detection, and Scrubber System .....................................5

2.1.2.10 Magnet and Magnet Traversing System ...........................................................

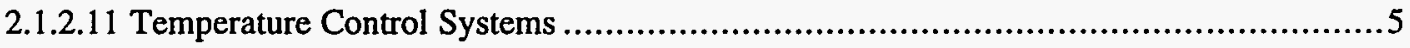

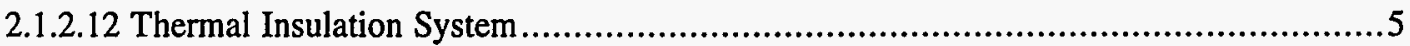

2.2 Design Requirements and Operational Requirements .........................6

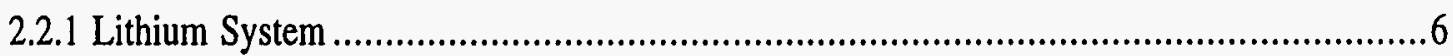

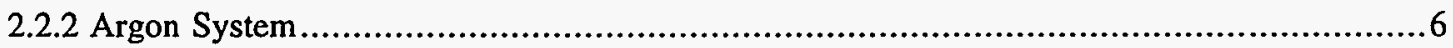

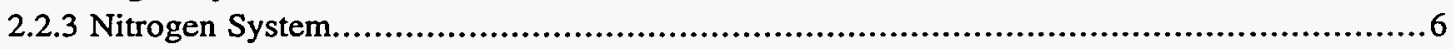

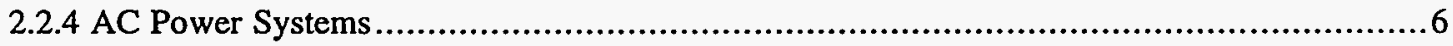

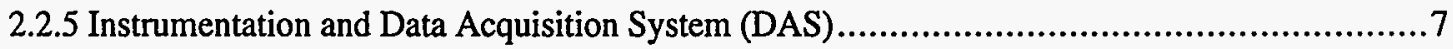

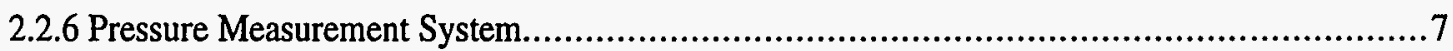

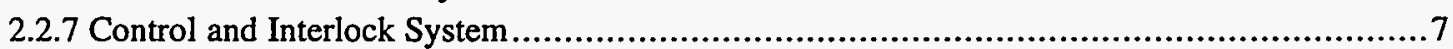

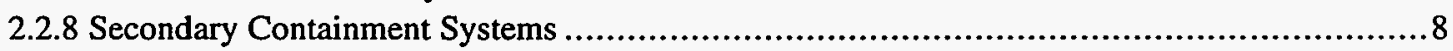

2.2.9 Leak Detection, Smoke Detection, and Aerosol Scrubber Systems................................. 8 


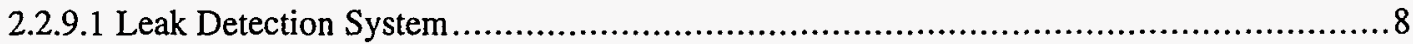

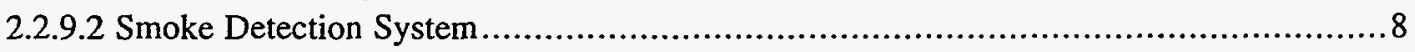

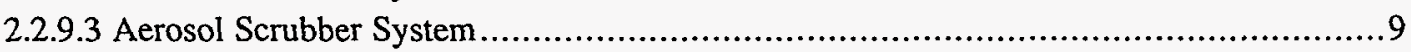

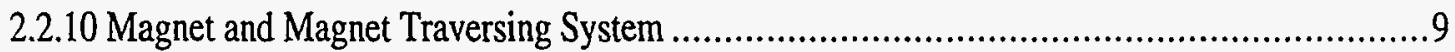

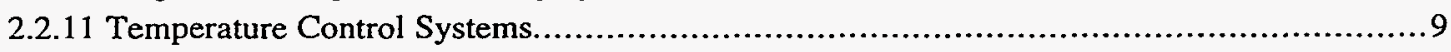

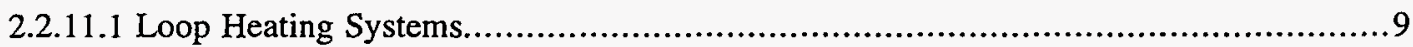

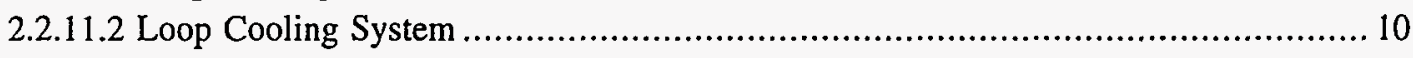

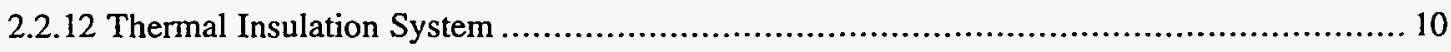

2.3 Structural Requirements ................................................ 0

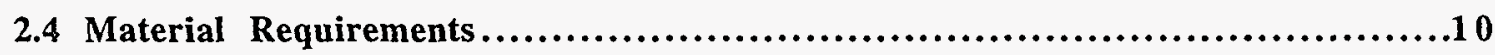

2.5 System Configuration and Essential Features..............................10

2.6 Maintenance.............................................................1 1

2.7 Instrumentation and Control.............................................. 2

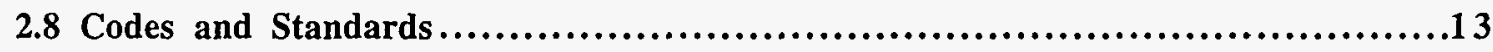

2.9 Reliability Assurance...................................................13

3. DESIGN DESCRIPTION ....................................................13

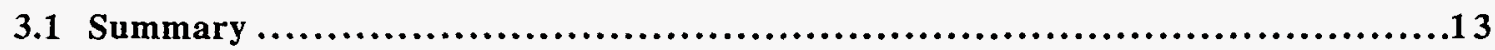

3.2 Detailed System Description.............................................14

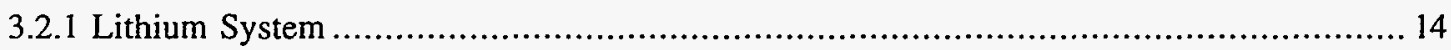

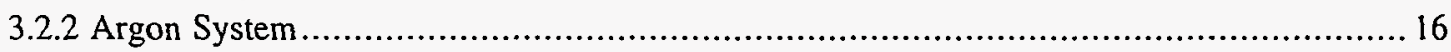

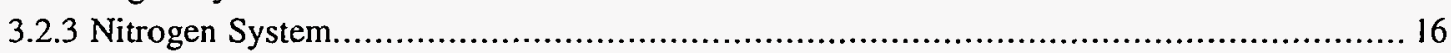

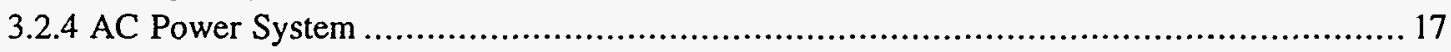

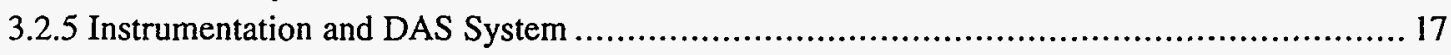

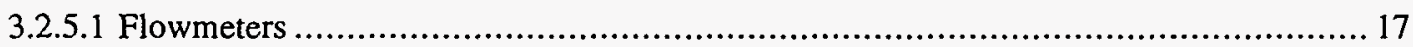

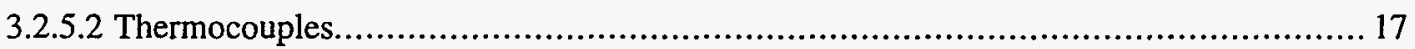

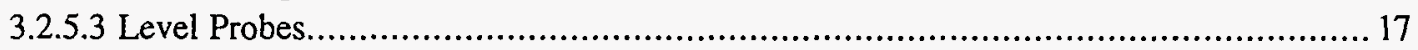

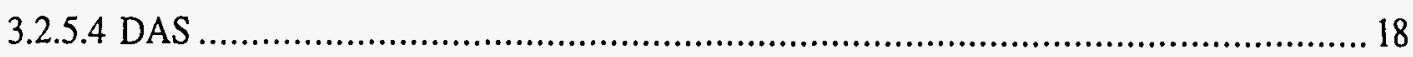




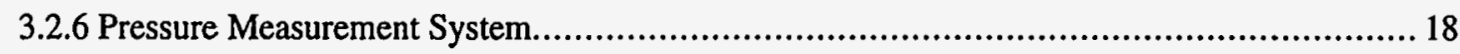

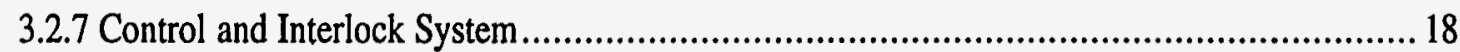

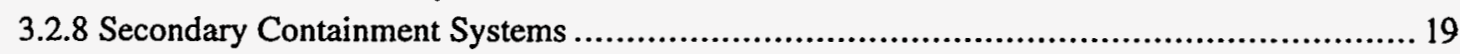

3.2.9 Leak Detection, Smoke Detection, and Scrubber System ....................................... 20

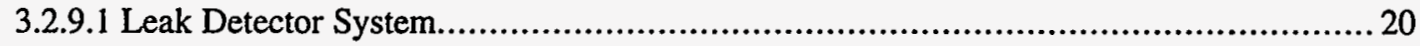

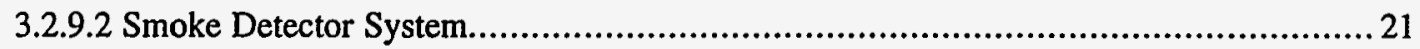

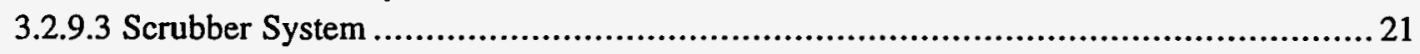

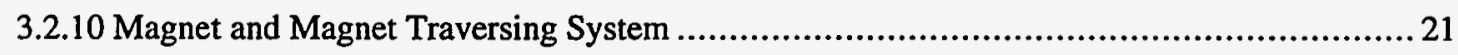

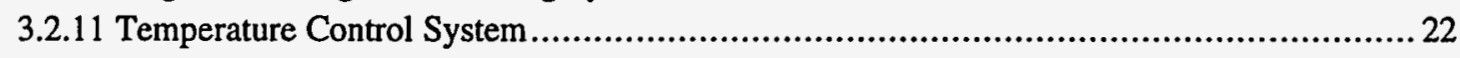

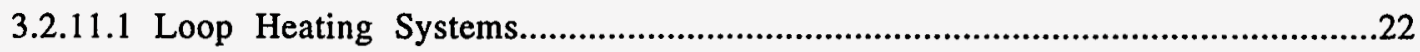

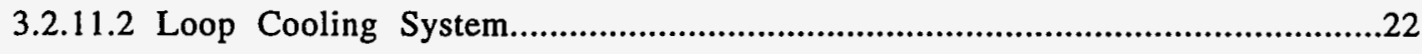

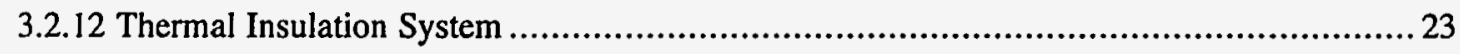

3.3 Component Design Descriptions...........................................23

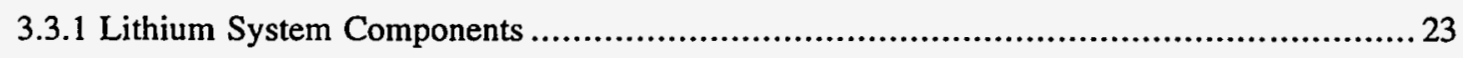

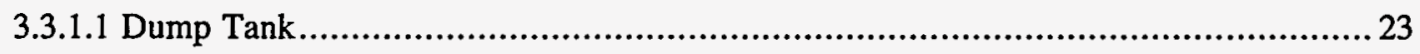

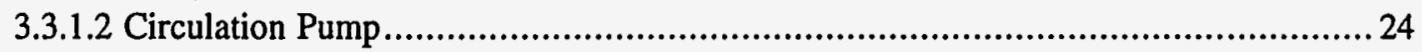

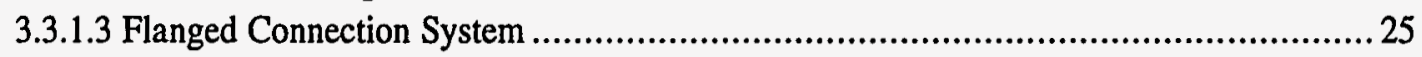

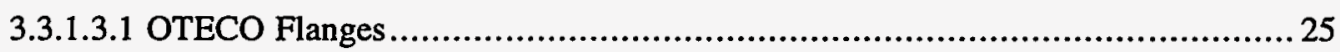

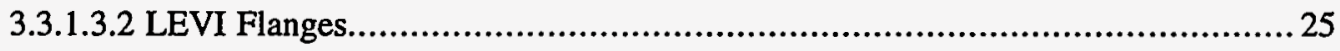

3.3.1.3.3 ANSI Weldneck Flanges............................................................. 25

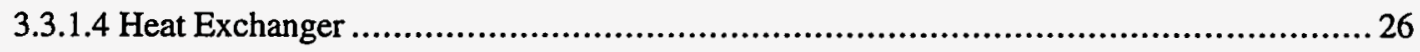

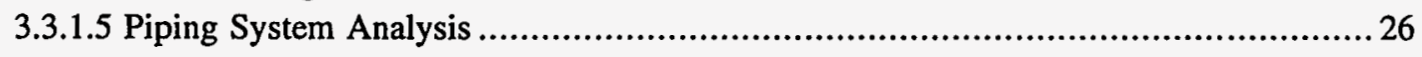

\section{SYSTEM LIMITATIONS, SET POINTS, AND PRECAUTIONS......27}

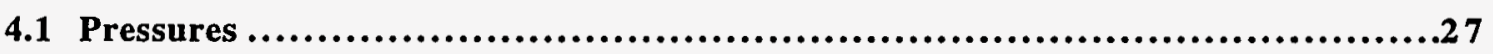

4.2 Temperatures.............................................................27

4.3 Flow Rates................................................................27

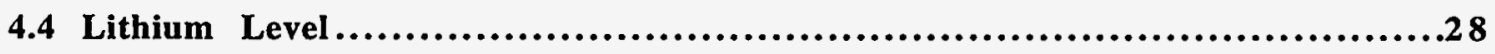

Acknowledgments......................................................................................29

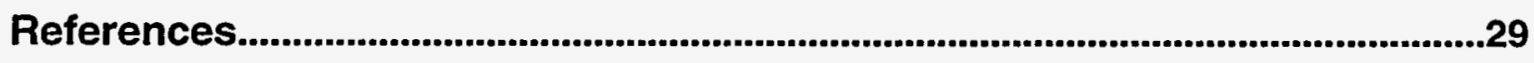




\section{LIST OF FIGURES}

FIGURE NO.

PAGE

1

ALEX lithium pump, dump tank and control valves......................... 30

2

ALEX pressure measurement system........................................ 31

3

ALEX NaK-filled heat exchanger and containment........................... 32

4

ALEX heater control cabinets.................................................... 33

5

ALEX heating system zones................................................... 34

$6 \quad$ ALEX loop lithium upgrade piping and instrumentation drawing, G0553-0160-DD. 


\title{
SUMMARY REPORT FOR ITER TASK - T68: MHD FACILITY PREPARATION for LI/N BLANKET OPTION
}

\author{
Claude B. Reed, Robert C. Haglund, Martha E. Miller, James R. Nasiatka \\ Igor R. Kirillov, Anatoli P. Ogorodnikov, Guennadi V. Preslitski, \\ and Guennadi P. Goloubovitch
}

\begin{abstract}
A key feasibility issue for the ITER Vanadium/Lithium breeding blanket is the question of insulator coatings. Design calculations show that an electrically insulating layer is necessary to maintain an acceptably low MHD pressure drop. To enable experimental investigations of the MHD performance of candidate insulator materials and the technology for putting them in place, the room-temperature ALEX (Argonne's Liquid Metal EXperiment) NaK facility was upgraded to a $300^{\circ} \mathrm{C}$ lithium system. The objective of this upgrade was to modify the existing facility to the minimum extent necessary, consistent with providing a safe, flexible, and easy to operate MHD test facility which uses lithium at ITER-relevant temperatures, Hartmann numbers, and interaction parameters. The facility was designed to produce MHD pressure drop data, test section voltage distributions, and heat transfer data for mid-scale test sections and blanket mockups. The system design description for this lithium upgrade of the ALEX facility is given in this document.
\end{abstract}




\section{SUMMARY}

The Vanadium/Lithium system has been the recent focus of ANL's Blanket Technology Program, and for the last two-three years, ANL's Liquid Metal Blanket activities have been carried out in direct support of the ITER breeding blanket task area. A key feasibility issue for the ITER Vanadium/Lithium breeding blanket is the question of insulator coatings. Design calculations, show that an electrically insulating layer is necessary to maintain an acceptably low MHD pressure drop in the current ITER design. To quickly begin experimental investigations of the MHD performance of candidate insulator materials and the technology for putting them in place, a test section with an insulating coating was prepared and installed in ALEX (Argonne's Liquid Metal EXperiment) in 1993. Aluminum oxide was chosen as the first candidate insulating material because it was being considered, in combination with NaK, for use in the ITER vacuum vessel and/or the divertor; and MHD performance tests could begin immediately in ALEX because NaK was already the working fluid in use. The results of this NaK testing, up to $200^{\circ} \mathrm{C}$, showed that the aluminum oxide coating could significantly reduce MHD pressure drop, almost as low as expected for perfect electrical insulation. These results were somewhat controversial however, because of the unknown extent of the disturbances caused by instrumentation penetrations.

Near the end of the fabrication phase of the aluminum oxide coated test section, it became clear that all future work must be as ITER-relevant as possible. This pointed ANL's liquid metal blanket activities in the direction of performing testing on vanadium components using lithium as the working fluid. Consequently, the decision was made to convert ALEX from an essentially room temperature $\mathrm{NaK}$ facility to a $300^{\circ} \mathrm{C}$ lithium facility. This upgrade was undertaken in parallel with finishing up the previously planned NaK testing. The objective of the upgrade was to modify the existing facility to the minimum extent necessary, consistent with providing a safe, flexible, and easy to operate MHD test facility which uses lithium at ITER-relevant temperatures, Hartmann numbers, and interaction parameters. The upgraded facility was designed to produce MHD pressure drop data, test section voltage distributions, and heat transfer data for mid-scale test sections and blanket mockups. The system design description for this lithium upgrade of the ALEX facility is given here. 


\section{INTRODUCTION}

The Vanadium/Lithium system has been the recent focus of ANL's Blanket Technology Program, and for the last two-three years, ANL's Liquid Metal Blanket activities have been carried out in direct support of the ITER breeding blanket task area. A key feasibility issue for the ITER Vanadium/Lithium breeding blanket is the question of insulator coatings. Design calculations, Hua and Gohar [1], show that an electrically insulating layer is necessary to maintain an acceptably low MHD pressure drop in the current ITER design. To quickly begin experimental investigations of the MHD performance of candidate insulator materials and the technology for putting them in place, a test section with an insulating coating was prepared and installed in ALEX (Argonne's Liquid Metal EXperiment) in 1993. Aluminum oxide was chosen as the first candidate insulating material because it was being considered, in combination with NaK, for use in the ITER vacuum vessel and/or the divertor, Natesan et. al. [2]; and MHD performance tests could begin immediately in ALEX because NaK was already the working fluid in use. The results of this NaK testing, up to $200^{\circ} \mathrm{C}$, showed that the aluminum oxide coating could significantly reduce MHD pressure drop, Reed, et. al. [3], almost as low as expected for perfect electrical insulation. These results were somewhat controversial however, because of the unknown extent of the disturbances caused by instrumentation penetrations.

Near the end of the fabrication phase of the aluminum oxide coated test section, it became clear that all future work must be as ITER-relevant as possible. This pointed ANL's liquid metal blanket activities in the direction of performing testing on vanadium components using lithium as the working fluid. Consequently, the decision was made to convert ALEX from an essentially room temperature $\mathrm{NaK}$ facility to $\mathrm{a} 300^{\circ} \mathrm{C}$ lithium facility. This upgrade was undertaken in parallel with finishing up the previously planned NaK testing. The objective of the upgrade was to modify the existing facility to the minimum extent necessary, consistent with providing a safe, flexible, and easy to operate MHD test facility which uses lithium at ITER-relevant temperatures, Hartmann numbers, and interaction parameters. The upgraded facility was designed to produce MHD pressure drop data, test section voltage distributions, and heat transfer data for mid-scale test sections and blanket mockups at Hartmann numbers $(M)$ and interaction parameters $(N)$ in the range of $10^{3}$ to $10^{5}$ in lithium at $300^{\circ} \mathrm{C}$.

The facility consists of a piping loop used to circulate lithium through a transverse magnetic field. The major loop components include a test section, heat exchanger, dump tank, pump, gas filters, flow meters, control valves, variable speed motor drive and magnet. Lithium (Li) is used as the liquid-metal working fluid because it is the coolant of choice for fusion reactors and helps produce conditions as close as possible to reactor relevant conditions, given the size and strength of the ALEX magnet. The system design description for this lithium upgrade of the ALEX facility is given here. 


\section{FUNCTIONS AND DESIGN REQUIREMENTS}

\section{$2.1 \quad$ Functions}

\subsubsection{Overall Loop Functions}

There are three primary functions of the Fusion LMMHD facility, also referred to as the Argonne Liquid Metal Experiment (ALEX). They are to provide:

- a continuous, steady isothermal flow (up to $300^{\circ} \mathrm{C}$ ) of lithium to a given test section;

- a steady-state magnetic field across a given test section; and,

- data acquisition services for collecting and storing data from experiments.

\subsubsection{System Functions}

The ALEX loop is comprised of ten systems which provide both the experimental conditions and the safety features that assure operations are in compliance with environmental, health and safety requirements. The systems and their functions are as follows:

\subsubsection{Lithium System}

Provides the capability to circulate an isothermal flow of the working fluid through a test section and constitutes the primary barrier between the lithium and the environment.

\subsubsection{Argon System}

Provides an inert cover gas inside the lithium primary system and also a motive force for pushing the lithium out of the dump tank and into the loop piping.

\subsubsection{Nitrogen System}

Provides compressed nitrogen from gas cylinders to operate the pneumatically-actuated flow control valve.

\subsubsection{AC Power System}

Provides AC power at proper voltages, with proper over-current protection, to the pump, instruments, heating systems, and other loop AC devices. 


\subsubsection{Instrumentation and Data Acquisition System}

(DAS)

Provides a means to monitor loop operation, and to collect and store experimental data from the loop and test section.

\subsubsection{Control and Interlock System}

Provides a safety system to assure that startup, operation and shutdown operations are performed in proper sequence so that equipment is not damaged and lithium is not released.

\subsubsection{Pressure Measurement System}

Provides a system to collect MHD pressure drop data from various test sections.

\subsubsection{Secondary Containment System}

Provides a preengineered collection area for any lithium leaks from the primary system, NaK from the pressure measurement system, or NaK from the heat exchanger annulus. It also confines any oxide aerosols and directs them to the scrubber system.

\subsubsection{Leak Detection, Smoke Detection, and Scrubber System}

Provides early detection of NaKlithium leaks, detection of NaK/lithium smoke, and scrubbing of the reacted NaKlithium aerosols from the air in the Secondary Containment System before it is released to the atmosphere.

\subsubsection{Magnet and Magnet Traversing System}

Provides a transverse magnetic field at the test section and a means to traverse the magnet.

\subsubsection{Temperature Control Systems}

Adds or removes (FUTURE) heat as necessary to maintain desired experiment temperature.

\subsubsection{Thermal Insulation System}

Provides easily removable, rugged, thermal insulation on loop piping and other heated components. 


\subsection{Design Requirements and Operational Requirements}

\subsubsection{Lithium System}

The working fluid shall be lithium (Li). The loop shall be designed to operate with a maximum operating temperature of $350^{\circ} \mathrm{C}\left(660^{\circ} \mathrm{F}\right)$. Loop operation may be either isothermal or with the test section heated.

To facilitate component installation and removal, the use of both "OTECO" and ANSI bolted flange connections is permissible, but the number of such connections shall be minimized.

When steady test cònditions are required, the lithium flowrate shall remain constant throughout a test condition within $+/-5 \%$ of set point.

\subsubsection{Argon System}

The argon system shall provide argon of sufficient purity to be used as a cover gas for all Naklithium wetted surfaces. The purity required is $99.999 \%$ pure with less than $1 \mathrm{ppm}$ oxygen and water. The argon gas shall be supplied at pressures required for the various operational modes:

(a) Standby, 14-34 kPag (2-5 psig); (b) Loop Filling, $35 \mathrm{kPag}$ (5 psig); and (c) Purging, $7-207 \mathrm{kPag}(1=30$ psig).

\subsubsection{Nitrogen System}

The nitrogen system, used to operate the pneumatic flow control valve, shall deliver $.55 \mathrm{MPa}(80 \mathrm{psig})$ to drive the actuator and deliver a continuously variable pressure from $21-103 \mathrm{kPa}(3-15 \mathrm{psig})$ required for positioning the valve.

\subsubsection{AC Power Systems}

The AC power system shall provide the necessary electrical power to the loop equipment, at the proper voltage and current, with proper over-current protection. 


\subsubsection{Instrumentation and Data Acquisition System (DAS)}

Instrumentation shall be provided to safely operate, diagnose problems in loop operation, and collect engineering data specified by any particular test matrix. Pressure gauges, pressure transducers, thermocouples, flowmeters and level indicators shall be in appropriate positions on the loop for the monitoring of critical loop component performance (pump, test section, valves, gas filters, heat exchangers, etc.) All instrumentation required for the operation of the loop shall have readout indicators which are located on the front panel of the loop control cabinet. Selected loop instrumentation and specified test instrumentation outputs shall be read by the DAS and stored for subsequent data reduction and analysis.

\subsubsection{Pressure Measurement System}

A pressure measurement system shall be provided which permits measurement of MHD pressure drop from insulated wall test sections which are expected to produce an axial pressure drop of approximately $500-1200 \mathrm{~Pa}\left(2-5\right.$ in. $\mathrm{H}_{2} \mathrm{O}$ ) across the full length of the magnetic field.

\subsubsection{Control and Interlock System}

This system is required to prevent loop operation in an unsafe manner or in a configuration which could result in damage to equipment. Specifically, the system shall have the following design objectives: to prevent pump cavitation; to assure the loop is full of lithium prior to starting the pump, and; to prevent lithium from overflowing in surge tank \#1 (surge tank inside loop equipment room).

In addition, if NaKlithium or any smoke is detected or if the EMERGENCY STOP button is pressed, the pump shall shutdown, the loop shall be drained back into the dump tank, the aerosol scrubber system shall automatically start, and the fire department shall be notified.

Because of the slow time response of the heating systems, and because the heater systems shall have built-in, redundant, over-temperature protection, the heater systems shall not be required to be shutdown by an EMERGENCY STOP button. 


\subsubsection{Secondary Containment Systems}

The NaK/ithium piping/tubing, surge tanks, dump tank, etc. serve as the primary barrier between the NaKlithium and the environment. The secondary containment systems shall provide a collection area for any NaKlithium leaks and confine any NaK/Li-oxide smoke and direct it to the aerosol scrubber system. Secondary containment shall enclose all bolted flange joints and all penetrations in the NaKlithium systems. The purposes of the secondary containment systems are:

- to prevent direct contact between a NaKlithium leak and the concrete floor;

- to prevent direct contact between a NaK/lithium leak and the magnet coils;

- to prevent major, uncontrolled leaks of NaK/ithium aerosol smoke into the Building 370 high bay;

- to form a confinement and inlet ducting system for the scrubber system.

The secondary containment systems shall not unduly restrict access to the NaK/lithium system components.

\subsubsection{Leak Detection, Smoke Detection, and Aerosol Scrubber Systems}

\subsubsection{Leak Detection System}

The leak detection system shall provide audible and visible alarm of any NaKlithium leaks from the liquid metal systems. The leak detectors shall be located at all credible sources of NaK/lithium leaks (non-welded connections). Individual leak detector indicators shall be provided to allow an operator to locate a NaK/ithium leak quickly when an alarm is initiated.

\subsubsection{Smoke Detection System}

The smoke detection system shall be capable of sensing the presence of NaKlithium aerosols in the loop enclosure room, starting the aerosol scrubber system, and alerting the Site Fire Department. 


\subsubsection{Aerosol Scrubber System}

The aerosol scrubber system shall be able to draw aerosols generated from a NaKlithium fire anywhere in the secondary containment system. The scrubber shall remove most of the aerosols and render the exhaust air suitable for discharge to the environment. The scrubber shall operate either automatically on a signal from the smoke detector or manually.

\subsubsection{Magnet and Magnet Traversing System}

The magnet and its power supply shall be capable of producing and maintaining a required applied magnetic field strength to within $\pm 0.5 \%$ of the set point. The magnet shall have a $20.3 \mathrm{~cm}$ (8 inch) gap.

The magnet traversing system shall be capable of traversing a $58,000 \mathrm{~kg}$ (64 ton) magnet along the test section $\pm 1.22 \mathrm{~m} \mathrm{(} \pm 4 \mathrm{ft}$ ) from a central position. The speed of the magnet traverse shall be such that the magnet can be stopped at predetermined locations within $\pm .025 \mathrm{~cm}$ (.010 inch) and that a full $2.4 \mathrm{~m}$ traverse can be completed in as little as 5 minutes. The magnet traversing system shall have a design lifetime of more than 729,000 full length traverses.

\subsubsection{Temperature Control Systems}

\subsubsection{Loop Heating Systems}

The loop heating systems shall be capable of heating and controlling the temperature of the loop piping, dump tank, and miscellaneous components as 16 separate and independent zones. Nine of the zones shall be capable of controlling up to $10 \mathrm{~kW}$ of heating power, six shall be capable of controlling up to $6 \mathrm{~kW}$, and the dump tank heating zone shall be capable of controlling up to $14.8 \mathrm{~kW}$. When steady thermal test conditions are required, the temperature within each zone shall remain constant throughout a test condition within $\pm 2^{\circ} \mathrm{C}$.

The dump tank heating system shall be capable of raising the Li-filled dump tank from room temperature to $300^{\circ} \mathrm{C}$ within 24 hours, with operator intervention only during a single 8-hour shift within the 24-hour period.

Each of the remaining piping or component heating systems shall be capable of raising the empty piping or component in a single zone from room temperature to $300^{\circ} \mathrm{C}$ within 4 hours, without operator intervention. 


\subsubsection{Loop Cooling System}

(FUTURE)

\subsubsection{Thermal Insulation System}

The thermal insulation system shall be capable of reducing the temperature of the outside non-metal surfaces exposed to possible contact by personnel to less than $70^{\circ} \mathrm{C}\left(156^{\circ} \mathrm{F}\right)$. Metal surfaces which may be contacted by personnel shall be below $49^{\circ} \mathrm{C}$ $\left(120^{\circ} \mathrm{F}\right)$.

\section{$2.3 \quad$ Structural Requirements}

The loop design conditions are:

$\begin{array}{ll}\text { Design pressure: } & \text { 1.MPag (150 psig) } \\ \text { Design flow: } & 22 \mathrm{l} / \mathrm{s}(350 \mathrm{gpm}) \\ \text { Design Temperature: } & 350^{\circ} \mathrm{C}\left(660^{\circ} \mathrm{F}\right)\end{array}$

The loop supports are required to support the mechanical loads of the loop components and the working fluid. The magnet support shall be designed to carry a load of $58,000 \mathrm{~kg}$ (64 tons).

\section{$2.4 \quad$ Material Requirements}

All wetted material surfaces shall be compatible with $\mathrm{NaK}$ or $\mathrm{Li}$, as appropriate. The preferred material is 304 stainless steel with the following exceptions: (a) Carbon steel: the bellows-seal valve; (b) Gasket and sealing materials: Lava (Magnesium Silicate), Nickel, and Graphite (trade name Grayfoil); (c) Miscellaneous items: SiC pump bearings, and WC pump shaft surface.

\subsection{System Configuration and Essential Features}

The loop is located in the west end of the high-bay area of Building 370 . The loop test section is oriented in a horizontal position with a small slope to aid in draining. The lithium working fluid is stored in a dump tank, when the loop is not operating, under an argon cover gas. The lithium drains automatically into the dump tank upon shutdown of the pump. Lithium pockets are limited to PV-101 and the pump casing. The dump tank has the lowest component elevation in the loop. The loop drip pan forms the base of a metal enclosure (loop equipment room) around the major loop components. The drip pan protects the concrete floor under the loop from a lithium system spill or leak. An additional pan surrounds the dump tank. The following major loop components are located outside the metal enclosure: test section, magnet and magnet traversing system, heat exchanger, and NaK-filled pressure measurement system. 
The magnet is protected from a test section NaKlithium leak or spill by a nonmagnetic stainless steel tray and tray cover. Test sections utilize "OTECO" type flange connections at each end. Sheet metal boxes at each end of the test section provide terminations for the tray as well as permit removal and installation of test sections. The boxes and the tray are ducted to the loop equipment room. The loop equipment room is ducted to a wet scrubber system for removal of combustion product aerosols which may be produced by NaKlithium reactions or fires. The lithium circulation pump is a Chempump GVHSH-3S centrifugal pump. The pump is an enclosed canned rotor pump with no rotating seals. Flow rate is controlled by adjusting the pump speed and throttling bellows-sealed valves.

The flow of lithium is out of the dump tank, through the circulation pump, in and out of the test section, and through the heat exchanger. The flow than can go through either or both of the following parallel flow paths: a low flow path for flows ranging from the minimum to $9.5 \mathrm{Vs}$ (150 gpm), and a high flow path for flows ranging from $9.5 \mathrm{l} / \mathrm{s}$ to the maximum. After passing through the above flow paths, the lithium returns to the dump tank.

An argon cover gas is maintained inside the lithium and pressure measurement systems at all times. The argon is delivered from standard compressed gas cylinders and is $99.999 \%$ pure, with $10 \mathrm{ppm}$ of the following impurities: $\mathrm{O}_{2}, \mathrm{H}_{2} \mathrm{O}$, $\mathrm{N}_{2}$, THC, and $\mathrm{CH}_{4}$ The argon system includes argon purifiers which are capable of reducing the $\mathrm{O}_{2}$ and $\mathrm{H}_{2} \mathrm{O}$ levels to less than $10 \mathrm{ppm}$.

The magnet is an iron-core, water-cooled electromagnet having the following pole face dimensions: Width: $76 \mathrm{~cm}$ (30 in), Length: $83 \mathrm{~cm}$ (72 in), Gap: $20.3 \mathrm{~cm}$ (8 in). The maximum magnetic field intensity is 2.0 Tesla, with the following maximum uniformities: axial non-uniformity: $B / B_{0}= \pm 0.5 \%$; lateral non-uniformity: $B_{z} / B_{0}= \pm$ $0.5 \%$.

In the pressure measurement system, the pressure transducers are separated from the high-temperature lithium working fluid by NaK-filled tubing and metal diaphragms, thus permitting measurement of pressures in the lithium with existing pressure transducers.

\subsection{Maintenance}

All NaK/lithium piping $1 / 2^{\prime \prime}$ and over is butt welded except where component removal for maintenance dictates a flanged connection. Specifically, the following components are flanged in: circulation pump, test section ("OTECO" connection); bellows-seal valve HV-101; and dump tank.

A minimum of 6 inches of clearance from floors, ceilings and walls is maintained for ease of component removal. 


\subsection{Instrumentation and Control}

The circulating pump is powered by a solid state, variable frequency, variable torque $A C$ drive. The $A C$ drive is capable of running the pump at speeds from $690 \mathrm{rpm}$ to $3450 \mathrm{rpm}$ (full rated speed). The output speed of the AC drive, in percent, is displayed on the front panel of the unit. The AC drive maintains the pump speed constant within $\pm 1 \%$ of set point. The pump speed is continuously variable between the above given limits.

Instrumentation is provided for measuring the lithium system pressure at the following locations: loop surge tank cover gas, and dump tank cover gas.

These pressures are labeled and displayed at the control panel in psig. In addition, the following lithium system pressures are indicated by local pressure gauges: dump tank cover gas, and surge tank cover gas.

Lithium system temperatures are measured at the inlet and outlet of the test section, and at the outlet of the heat exchanger. The temperatures are displayed at the control panel in degrees Fahrenheit ( $\left.{ }^{\circ} \mathrm{F}\right)$. The cooling water temperature rise for the magnet cooling water is measured and displayed at the control panel in ${ }^{\circ} \mathrm{F}$. The lithium piping temperatures at several locations are recorded by the DAS. NaKlithium system temperature measuring devices do not penetrate the primary pressure boundary except in the dump tank.

The magnetic field strength, in Tesla, is displayed at the control panel and recorded by the DAS.

Lithium flow rate is measured in the main flow loop and in the low flow loop as well. These flow rates are displayed at the control panel in GPM and recorded by the DAS.

Lithium level detectors indicate a full and low level in the dump tank. The lower level probe in the dump tank LS101, is a sheathed, triple junction, type K, thermocouple which also measures the lithium temperature at three elevations within the dump tank. In the surge tank, low, high, and overflow levels are indicated. All lithium levels shall be displayed at the control panel by means of status indicator lights.

Both the argon and nitrogen systems are instrumented to measure the high (bottle supply) and low side pressures of each system. Argon gas flow rate is indicated using a simple rotameter. Pressure regulators are provided for each system. A special pressure regulator to control the pneumatically operated flow control valve is also provided.

The experiment differential pressure is measured at the test section inlet and outlet. Pressure-transmitting, fluid-sealed diaphragms transmit loop pressure to a NaKfilled pressure measurement system. This allows the pressure transducers to be filled with a liquid at room temperature. 


\subsection{Codes and Standards}

The specifications, codes and standards applicable to design, construction, inspection and testing are listed as follows:

$\begin{array}{ll}\text { Pump } & \text { Manufacturer's Standards } \\ \text { Dump tank } & \text { ASME Section VIII, Div. 1 } \\ \text { Heat exchanger } & \text { ASME Section VIII, Div. 1 } \\ \text { Surge tank } & \text { Manufacturer's Standards } \\ \text { Valves } & \text { Manufacturer's Standards } \\ \text { Loop piping } & \text { ANSI B31.1 } \\ \text { ANSI flanges } & \text { ANSI B31.1 } \\ \text { OTECO flanges } & \text { Manufacturer's Standards } \\ \text { Scrubber } & \text { Manufacturer's Standards } \\ \text { AC drive } & \text { Manufacturer's Standards } \\ \text { Test section } & \text { ANSI B31.1 } \\ \text { Magnet } & \text { Existing equipment } \\ \text { Electrical Service } & \text { National Electrical Code } \\ \text { Magnet Support System } & \text { ASME Section VIII Div.1 }\end{array}$

\subsection{Reliability Assurance}

No sub-systems are designated as reliability-critical items. Because of the experimental nature of the tests to be conducted, sub-system redundancy, etc. is not considered necessary. In case of a power failure, for example, the lithium will simply drain to the dump tank.

\section{DESIGN DESCRIPTION}

\subsection{Summary}

Plan and elevation views of the Fusion LMMHD facility are shown in drawings G0553-0008-DE and G0553-0095-DE. This is a closed loop system, circulating lithium through a horizontal test section in the presence of an externally applied magnetic field. An argon cover gas and disposable argon purifier system minimize NaK/lithium oxidation. The loop proper is contained within a metal enclosure which is ducted to a wet scrubber system. The scrubber starts automatically in the event of a NaKlithium fire.

The lithium circulation flow rate is controlled by an $A C$ drive and flow control valves. Lithium temperature is controlled by a 16 -zone electric heater system, and lithium pump intake pressure is set by the argon cover gas system.

Both local instrumentation and control panel-mounted instrumentation are provided. A DAS collects and stores loop and test section data for later analysis. 


\subsection{Detailed System Description}

The ALEX loop is a pressurized, closed loop system which can be used for performing high temperature isothermal liquid-metal MHD experiments. The working fluid, $\mathrm{Li}$, is maintained under an argon cover gas to minimize the formation of lithium oxides and other lithium compounds. The overall system consists of the following major sub-systems:

- Lithium System

- Argon System

- Nitrogen System

- AC Power System

- Instrumentation and DAS System

- NaK-Filled Pressure Measurement System

- Control and Interlock System

- Secondary Containment Systems

- Leak Detection, Smoke Detection and Scrubber System

- Magnet and Magnet Traversing System

- Heating System

A detailed description of each major sub-system follows:

\subsubsection{Lithium System}

Refer to the following three drawings in connection with the description of the lithium system:

1. G0553-0159-DE, "ALEX Loop Lithium Upgrade Piping Isometric"

2. G0553-0008-DE, "Fusion LMMHD Experimental Loop Plan and Elevation"

3. G0553-0160-DD (Fig. 5), "ALEX Loop Lithium Upgrade Piping and Instrumentation." 
The lithium system consists of the following major components:

- Dump tank - for storing the lithium between experiment runs

- Circulation pump - for pumping the lithium through the loop and test section

- Test section - for collecting experimental data in the presence of a magnetic field

- Heat exchanger - for removing heat from the NaKMithium to maintain desired operating conditions (FUTURE)

- Heat exchanger surge tank - for collecting Ar gas bubbles purged from the heat exchanger

- Loop surge tank - for collecting Ar gas from loop piping, valves, etc.

- Valves - for adjustment of the lithium flow

- Flanged connection system - for connecting components, including the test section, and piping segments together.

By means of the above components, the lithium system contains, circulates, and controls the flowrate and temperature of the Li. The lithium is pumped out of the dump tank, through the test section, the heat exchanger, and the primary EM flowmeter (FM102) before returning to the dump tank. There are two selectable separate flow paths from the primary EM flowmeter to the dump tank. These two paths can be seen on either dwg. G0553-0159-DE or G0553-0160-DE. The flow can be routed through these two paths to meet the needs of an experiment. The typical flow path for testing, flows $\leqslant 9.5 \mathrm{l} / \mathrm{s}(150 \mathrm{gpm})$ is through the $3.8 \mathrm{~cm}(1.5 \mathrm{in}) \mathrm{EM}$ flow meter, FM103, and the bellows-sealed manual control valve HV101.

All lithium system piping is $7.62 \mathrm{~cm}$ ( 3 in) (Sch. 40) except the low flow leg passing through FM103, which is $3.81 \mathrm{~cm}$ (1.5 in) (Sch. 40).

There are three flange types used in the flanged connection system, "OTECO", LEVI, and ANSI weld neck. 


\subsubsection{Argon System}

Refer to dwg. G0553-0160-DD (Fig. 5) for details on the argon system. The argon system consists of 3 cylinders of high purity compressed argon, associated valving, pressure regulators, argon rotameter, and an argon purifier. The schematic arrangement of the components is shown on the above drawing. The argon system serves the following two functions:

1. it provides an inert cover gas over the NaKlithium to minimize oxidation, and

2. it is used to force the lithium out of the dump tank and up into the loop, prior to initiation of lithium circulation.

The argon system is used to raise the lithium up out of the dump tank and into the loop as follows: After closing the following valves: HV101, PV101, and HV219, argon pressure is applied to the dump tank, forcing lithium out of the dump tank through the pump, the test section, the heat exchanger and up to the closed valves HV101 and PV101. The argon level continues to rise in the loop until it trips the low level indicator in the surge tank. At this point, the pump may be energized using the AC drive. The pump speed is increased until the pump discharge pressure is approximately $34.5 \mathrm{kPa}(5 \mathrm{psi})$ higher than the dump tank pressure. At this point HV101 and PV101 can be opened and adjusted to establish lithium circulation.

\subsubsection{Nitrogen System}

The nitrogen system is shown schematically on dwg. G0553-0160-DD (Fig. 5). The sole purpose of the nitrogen system is to provide compressed nitrogen to actuate the pneumatically operated lithium flow control valve, PV101. Three pressure regulators are provided to deliver the following three $\mathrm{N}_{2}$ pressures:

- PR501 - provides $552 \mathrm{kPag} \mathrm{Pa} \mathrm{(80} \mathrm{psig)} \mathrm{supply} \mathrm{N}_{2}$ pressure,

- PR503 - provides $69 \mathrm{kPa}$ (10 psig) cushion load $\mathrm{N}_{2}$ pressure, and

- PR502 - provides the 21-103 $\mathrm{kPag} \mathrm{Pa}$ (3-15 psig) control signal to open or close the valve. At $21 \mathrm{kPag} \mathrm{Pa}(3 \mathrm{psig})$ the valve is fully closed and at $103 \mathrm{kPa}$ (15 psig) the valve is fully open. 


\subsubsection{AC Power System}

The AC power system is shown on dwg. G0553-0043-DC. The purpose of this system is to provide $A C$ service to the pump, heating systems, instruments, lights, scrubber, and other loop $A C$ devices. A variable torque, variable frequency, AC drive (Emerson model AS5290, type 5VT30) is used to control the pump speed and hence the lithium flow rate. All other AC power at the proper voltage and with proper over-current protection is provided using standard components as shown on the above drawing. Ground fault interrupters are installed on some 120 VAC circuits, which are so labeled.

\subsubsection{Instrumentation and DAS System}

Instrumentation locations are shown schematically on drawing G0553-0160-DD (Fig. 5) and isometrically on G0553-0159-DE.

\subsubsection{Flowmeters}

Flowmeters employed are DC electromagnetic flowmeters FM102 and FM103, made by Mine Safety Appliances and Sechrist Industries, respectively. Their calibration factors were determined by applying temperature- and working-fluid-dependent correction factors to NaK calibration factors. The NaK calibration factors were previously determined in ALEX by using NIST-traceable turbine flowmeters.

\subsubsection{Thermocouples}

An array of thermocouples of Types $K$ and $T$ are used throughout the loop.

\subsubsection{Level Probes}

CONAX level probes with Lava (magnesium silicate) packing are used. The electrodes are 300 series SS rod. 


\subsubsection{DAS}

Instruments that may be connected to the DAS include flowmeters, test section thermocouples, and the differential pressure measurement system. These instruments are so indicated on G553-0160-DD (Fig. 5) by a special symbol:

$$
\mathrm{O} \rightarrow>
$$

A block diagram showing the ALEX DAS and further details can be found in G0553-0061-SA "System Design Description for ALEX Data Acquisition System."

\subsubsection{Pressure Measurement System}

The Pressure Measurement System (PMS) employs NaK-filled pressure transmitters connected to three Rosemount Model 1151 DP differential pressure sensors. The three DP sensors have ranges of $(0-1.2,0-7.5$, and $0-25) \mathrm{kPa}\left(0-5 ", 0-30 "\right.$ and $0-100^{\prime \prime} \mathrm{H}_{2} \mathrm{O}$, respectively). The NaK-filled system transmits loop pressure to the DP sensors through pressuretransmitting diaphragm seals. The diaphragm seals are made of a single $0.015^{\prime \prime}$ thick stainless steel diaphragm welded to a housing. The housing is welded to the experiment test section on one side and connected to the NaK-filled DP sensors on the other. The system has limited NaK thermal expansion tolerance and hence a surge tank is included to accommodate operation during test section temperature changes, see Fig. 2.

\subsubsection{Control and Interlock System}

The control and interlock system was designed to achieve the following three objectives:

1. To prevent pump cavitation,

2. To assure the loop is full of lithium prior to starting the pump, and

3. To prevent lithium from overflowing in surge tank \#1 (surge tank inside loop equipment room).

To accomplish the first two objectives one set of interlocks was developed which restrict the conditions under which the pump can be started; he other set of interlocks was developed to restrict the conditions under which the pump will continue to operate, once started. The Control and Interlock system is described in detail in G0553-0164-SA, "System Design Description for the ALEX Loop Control and Interlock System." 


\subsubsection{Secondary Containment Systems}

To protect neighboring experiments and to assist in potential fire fighting efforts, major loop components including all flanged and threaded penetrations of the NaK/ithium piping are located inside metal containments. The main components of the loop, e.g., the pump, dump tank, flow control valves, and all of the ANSI flanges, are located inside a metal containment building, which has a metal floor.

A stainless steel "secondary" containment surrounds the test section including its flanged connections to the loop piping. This test section secondary protects the magnet coil windings from potential NaK/ithium leaks. It also contains and directs any combustion aerosols into the scrubber system. The metal thickness of the test section secondary is 1.5 $\mathrm{mm}\left(0.0598^{\prime \prime}, 16\right.$ gage). The test section secondary is composed of two "U"-shaped channels, one underneath the test section serving to catch any NaK/ithium spills or leaks, and a "U"-shaped cover to contain any aerosols. The cover is held in place by gravity. The secondary containment is not air tight; the negative pressure created by the scrubber system will minimize aerosol release.

All the pressure taps, pressure lines, transducers, and valves of the pressure measurement system are inside a secondary containment, as are the leak detectors, which are located at each position where a credible Naklithium leak is possible.

The non-welded connections on each end of the NaK-filled heat exchanger are surrounded by a $1.5 \mathrm{~mm}(0.0598 ", 16$ gage) stainless steel containment system made from cylindrical, flat-bottomed containers. Leak detectors are positioned at the bottom of each container. 


\subsubsection{Leak Detection, Smoke Detection, and Scrubber System}

\subsubsection{Leak Detector System}

The leak detection system consists of more than 20 sensors and a single detector chassis. The system detects NaKlithium leaks b y taking advantage of the high electrical conductivity of NaK/Li. Leak detector sensors are of two types:

\section{Low-temperature sensors:}

are printed circuit boards covered by rows of current paths etched into one side. Every other current path on each sensor board is common to the (t) side of a DC circuit while the other current paths are common to the $(-)$ side. When adjacent current paths are bridged by a drop or more of $\mathrm{NaK} / \mathrm{Li}$, the short circuit condition is detected by the chassis, giving both an audible tone and illuminating a light.

\section{High-temperature sensors:}

are comprised of a single loop of electrical hook-up wire wrapped around each ANSI flange, in the gap between the mating flanges. A portion of the high-temperature electrical insulation at the bottom of each loop of sensor wire is removed, so that any lithium leak will contact the wire and complete the electrical circuit between the flange and the high-temperature wire. This short circuit condition is detected by the chassis, giving both an audible tone and illuminating a light.

Each leak detector sensor is identified separately on the indicator panel so that NaKlithium leaks can be located quickly. Every flanged connection has a dedicated leak detector sensor. The locations and numbering system of the leak detector sensors are shown on drawing G0553-0160-DD (Fig. 6). 


\subsubsection{Smoke Detector System}

The smoke detector is a commercially available photo-electric device which initiates the following three actions when smoke is detected, it: (1) signals the ANL fire department, (2) starts the loop wet scrubber system, and (3) turns off the aerosol containment building exhaust fan.

\subsubsection{Scrubber System}

The scrubber system is a commercially available wet ventureeductor system which removes aerosols by scrubbing with fresh water in a converging-diverging hypermixing eductor. A hypermixing jet is created across a pressure drop of about $1.0 \mathrm{~m}$ of water. The scrubbed gases are separated from the water droplets by impaction on a horizontal surface of water. Chevrons serve as mist eliminators as the gas leaves the scrubbing tank. An induction fan raises the scrubbed gas pressure back up to slightly above atmospheric and ducts it to an exhaust stack in building 370 . Scrubber placement and approximate outline shape are shown on G0553-0008-DE.

\subsubsection{Magnet and Magnet Traversing System}

The magnet employed is a conventional iron core, water-cooled electromagnet. It is a "picture frame" design with saddle coil windings and coil end caps to minimize field fringing. The magnet was designed for and previously used as a beamline bending magnet in high energy physics experiments at ANL. The nominal field strength is 2.0 tesla (T) and the pole face dimensions are $0.76 \mathrm{~m}$ wide by $1.83 \mathrm{~m}$ long. The pole face gap has been upgraded to $20.3 \mathrm{~cm}$.

Within the gap, the uniformity of the field is typically $\pm 0.1 \%$. The quality of the field is much higher than is minimally required for these experiments.

The magnet is mounted on a bearing assembly which rolls on a hardened steel way. The way is horizontal and flat within $\pm 0.20 \mathrm{~mm}$. The roughly $5.8 \times 10^{4} \mathrm{~kg}$ (64 ton) magnet structure travels $\pm 1.22 \mathrm{~m}$ ( \pm 48 inches) about the axial midpoint of the test section along the hardened way. The magnet structure is traversed by a hydraulic piston system at a speed which is continuously variable between 0.14 and $1.23 \mathrm{~cm} / \mathrm{s}$. The magnet can be positioned at predetermined locations along the test section within \pm 0.010 inch. The traversing feature of the magnet provides a great flexibility in planning tests and collecting data. The traversing system is capable of 729,000 full length traverses before bearing replacement is necessary. The number of pressure taps, instrument penetrations, and voltage tap locations can be held to a minimum by moving the magnet with respect to a few fixed instrumented locations. 


\subsubsection{Temperature Control System}

\subsubsection{Loop Heating Systems}

The loop heating system consists of 16 independent zones of 208 VAC resistance-heated ceramic band heaters, see Fig. 5 . There are three power levels for heating zones; 6 ea. @ $6 \mathrm{~kW}, 9$ ea. @ $10 \mathrm{~kW}$, and one (dump tank) @ $14.8 \mathrm{~kW}$. The 6 and $10 \mathrm{~kW}$ heating zones are grouped into cabinets; all six $6 \mathrm{~kW}$ zones are in a single cabinet; the $10 \mathrm{~kW}$ zones are grouped three to each cabinet, see Fig. 4 . All zones have four main components:

Temperature controller; receives input from control thermocouple; solid state, PID.

Power controller; driven by temperature controller; SCR-based for zones $\geq 10 \mathrm{~kW}$, SSR-based for 6 kW zones.

High limit controller; monitors over-temp. thermocouple; digital for $6 \mathrm{~kW}$ zones, analog for all other zones.

Double break contactor; driven by high limit controller, interrupts heater power circuit to provide independent, redundant over-temperature protection.

This system is designed to permit the unattended maintenance of component temperatures such as the dump tank, pump, PV101, HV101, etc. thus minimizing startup time for loop circulation.

A thirty-channel digital thermocouple chart recorder/relay alam unit is provided for monitoring selected piping and component temperatures during heatup and operation.

\subsubsection{Loop Cooling System}

(FUTURE) 


\subsubsection{Thermal Insulation System}

Custom-made removable thermal insulation covers are provided for all major loop components except the test section. The insulation consists of $5 \mathrm{~cm}$ (2 inch) thick of ALPHAMAT-D ${ }^{\circledR} 100 \%$ fiberglass high-temperature insulation, with a natural fiberglass cloth and wire mesh inner liner, a silicone impregnated fiberglass cloth outer liner, Velcro ${ }^{\circledR}$ seam covers and belt straps. The 2 inch thick ALPHAMAT-D ${ }^{\circledR}$ and fiberglass cloth inner liner are useful up to $650^{\circ} \mathrm{C}\left(1200^{\circ} \mathrm{F}\right)$. The $\mathrm{k}$ factor for the $5 \mathrm{~cm}(2 \mathrm{inch})$ thick ALPHAMAT-D ${ }^{\circledR}$ is $110 \mathrm{~W} / \mathrm{m}^{3} \mathrm{~K}\left(0.5 \mathrm{BTU} / \mathrm{hr} / \mathrm{in} / \mathrm{ft}^{2} /{ }^{\circ} \mathrm{F}\right)$.

The test section, dump tank, pump body, "OTECO" flanges, and miscellaneous parts of the loop are insulated with ceramic fiber insulation, usually 1 and $2 \mathrm{~cm}$ thick blankets. Around the dump tank, ceramic fiber insulation is used in loose form.

\subsection{Component Design Descriptions}

In the Detailed System Description subsection, major individual components were listed and briefly mentioned. Component design descriptions for these major components are given below.

\subsubsection{Lithium System Components}

\subsubsection{Dump Tank}

The dump tank, which provides lithium storage when the loop is inactive between runs, is shown on dwg. G0553-0003-DD. The dump tank is fabricated of all welded construction using 20" STD. WT. $3 / 8^{\prime \prime}$ wall pipe. Standard $20^{\prime \prime}$ end caps are welded to the pipe to make a horizontal tank, $96^{\prime \prime}$ in overall length. Li-wetted materials of construction are ASTM-A-312, TP304L. The tank has five top penetrations, one for outflow of lithium and one for lithium inflow (both $3^{\prime \prime}$ sch. 40 pipe size). The lithium inflow penetration contains a splash sleeve as shown on dwg. G0553-0023-DB. The splash sleeve is a longitudinally slotted cylinder which fits inside the dump tank as shown on the above drawing. The purpose of the splash sleeve is to minimize the entrainment of gas bubbles into the pump suction line.

The third and fourth penetrations, are $1 / 2^{\prime \prime}-3000 \#$ threaded half couplings provided for lithium level sensing instrumentation. The fifth penetration is a 1 " sch. 40 pipe stub, provided for connection of the argon system and the pressure relief valve. The tank has two carbon steel angle shapes welded to the bottom of the tank for support. 
The lithium outlet pipe extends to within 1" of the bottom of the tank to minimize pump cavitation. The pipe is chamfered at a $30^{\circ}$ angle to help prevent vortex formation. A minimum argon cover gas pressure of $240 \mathrm{Pag}$ (5 psig) ( $8.5 \mathrm{~m}$ of $\mathrm{Li}$ ) is maintained in the dump tank during operation to prevent pump cavitation. See Fig. 1.

\subsubsection{Circulation Pump}

The circulation pump is a Crane Chempump, Model GVHSH-3S. This is a high-temperature canned motor, centrifugal pump. The pump has 300\# raised face flanges; $2.5 \mathrm{~cm}$ (1 in) discharge, $5.1 \mathrm{~cm}$ ( 2 in) suction. The pump has only one moving part - a rotor and impeller assembly which is driven by the rotating magnetic field of the induction motor.

Motor cooling and bearing lubrication are provided by the flow of circulating lithium through the motor section. A small portion of the discharge flow passes through a filter--fitted in the discharge neck of the pump casing--through the circulation tube, into the rear of the motor section and then through the rotor chamber, across the bearings, and back into the suction eye of the impeller.

The stator winding cavity of the pump is filled with air. Class C insulation is furnished. This, coupled with the air-filled stator cavity and the effective cooling and lubrication system incorporated in this Chempump, allows this unit to handle fluids at temperatures up to $343^{\circ} \mathrm{C}\left(\sim 350^{\circ} \mathrm{C}, 650^{\circ} \mathrm{F}\right)$.

All Li-wetted pump surfaces are 304/316 SS except for the WCcoated shaft, the $\mathrm{SiC}$ bearing material, and the nitrided thrust surface.

The pump is externally heated by two $6 \mathrm{~kW}$ each heating zones, one on each end of the pump. The pump is instrumented with 26 thermocouples for measuring the external surface temperature, for control, and for over-temperature. See Fig. 1. 


\subsubsection{Flanged Connection System}

\subsection{OTECO Flanges}

The "OTECO" flanges are used to connect the test section and the inlet and outlet adapters to each other and to the loop piping. "OTECO" flanges are a proprietary design having a metal to metal seal between the two 316SS hubs and a 17-4 PH SS seal ring; their pressure and temperature ratings are $12.7 \mathrm{MPa}$ and $540^{\circ} \mathrm{C}$, respectively. This flanged connection has been successfully used previously in ALEX with $300^{\circ} \mathrm{C} \mathrm{NaK}$.

\subsection{LEVI Flanges}

The test section has two flanged penetrations for LEVI probes, however, LEVI probes are not used in the early operation of the lithium upgrade. These flanges are sealed with blind flanges and nickel plated 321 stainless steel o-rings having dimensions of $29.97 \mathrm{~mm}$ OD (1.18 inch), $2.39 \mathrm{~mm}$ free height (0.094 inch), and $0.152 \mathrm{~mm}$ wall thickness ( $0.006 \mathrm{inch}$ ).

\subsection{ANSI Weldneck Flanges}

Standard, 300 series, $150 \#$ and $300 \#$ stainless steel ANSI weldneck flanges are used to connect several major components and piping segments together. Each flange configuration was analyzed to determine the recommended gasket seating load and recommended bolting torques according to "improved" ASME Code guidelines (which are far more rigorous than existing procedures). Analyses were also performed to determine the maximum allowable bolting torques based on stresses in the flanges themselves. A thermal stress analysis of these bolted joints lead to the use of Inconel 718 belleville washers (good to $705^{\circ} \mathrm{C}, 1300^{\circ} \mathrm{F}$ ) on each stud to assure the desired preload under all temperatures. A "sandwich" gasket design for sealing the ANSI flanges for lithium service is used. The "meat" of the sandwich is a $0.46 \mathrm{~mm}$ thick stainless steel sheet which was stamped with several corrugations to provide some measure of compressibility. The peak-to-peak thickness of the corrugations is about 1. $\mathrm{mm}$. The corrugated stainless steel is sandwiched between two sheets of $0.8 \mathrm{~mm}$ thick graphite (trade name "Grayfoil"); the overall thickness of the gasket, before installation, is about $3.6 \mathrm{~mm}$. Lithium can contact the graphite at the inner edge of the gasket. Polished, Grade B7, studs and Grade $2 \mathrm{H}$ nuts, coated with a silver-based thread lubricating compound were tightened with a torque wrench to the values obtained from the above described analyses. 


\subsubsection{Heat Exchanger}

The heat exchanger, shown on dwg. G0553-0013-DD, was designed by ANL. It is described in detail in G0553-0062-SA "Component Design Description for NaK/Li-NaK Heat Exchanger for ALEX", see Fig. 3.

\subsubsection{Piping System Analysis}

Thermal stress analyses were performed on the following components:

1. 3 inch $\mathrm{SCH} 40$ pipe:

THTB was used to perform a transient thermal analysis of an empty segment of 3 inch $\mathrm{SCH} 40$ pipe. The analysis modeled the thermal stresses under a single band heater at full power, separated from the neighboring heater by $91 \mathrm{~cm}(3 \mathrm{ft}$.) The results indicated that the thermal stresses were well within ASME code allowables.

\section{Dump tank:}

A steady state, 3D finite element analysis was carried out for the dump tank using COSMOS. The analysis used actual temperature differences measured during heatup as input; the heatup time was assumed so long that the thermal conditions were steady state. The resulting thermal stresses in the neighborhood of welds were well within ASME code allowables.

\section{Loop piping:}

The ANSIS code was used to perform a steady state piping flexibility analysis. The loop displacements and stresses developed when the loop was heat uniformly to $300^{\circ} \mathrm{C}$ were accommodated by redesigning the piping support system. The un-restrained stresses were well within ASME code allowables. 


\section{SYSTEM LIMITATIONS, SET POINTS, AND PRECAUTIONS}

\subsection{Pressures}

System set points of pressure regulators, safety relief valves and operating pressure limits are given below.

- Dump Tank Pressure

- $14-34 \mathrm{kPag}$ (2-5 psig), loop standby mode (lithium drained to dump tank)

- $\quad 34.5 \mathrm{kPag} \mathrm{(5} \mathrm{psig),} \mathrm{minimum} \mathrm{operating} \mathrm{pressure}$

- $207 \mathrm{kPag}$ ( $30 \mathrm{psig}$ ), maximum operating pressure (safety relief valve (SRV 201) set for 207 Pag (30 psig)

- Nitrogen System Pressure

- $690 \mathrm{kPag}$ (100 psig), supply pressure to PV101

- $69 \mathrm{kPag}$ ( 10 psig), cushion load pressure to PV101

- 21-103 kPag (3-15 psig), control signal pressure PV101.

\subsection{Temperatures}

Lithium system temperature is automatically controlled by adjusting the heater system temperature controller for the various zones of the loop.

- Maximum lithium operating temperature $350^{\circ} \mathrm{C}\left(660^{\circ} \mathrm{F}\right)$

- Minimum lithium operating temperature will be approximately $20^{\circ} \mathrm{C}$ above the melting point of the Li.

\subsection{Flow Rates}

Lithium flow rate course control is maintained by PV101 and HV101, depending on the needs of the experiment. Fine flow control is achieved by adjusting the output frequency of the AC drive. This is a manual, open loop control system.

- Maximum lithium flow rate - $28 \mathrm{l} / \mathrm{s}(440 \mathrm{gpm})$

- Minimum lithium flow rate $-0.063 \mathrm{l} / \mathrm{s}(1 \mathrm{gpm})$. 


\subsection{Lithium Level}

Lithium level probes are located in the dump tank, the surge tank, the inlet of the pump, the discharge of the pump, and in the 1-1/2 inch piping upstream of the flow control valve, HV101.

- Dump Tank

- low level: $17 \mathrm{~cm}$ (6.7 in) from bottom of tank (135 liters (36 gal) of $\mathrm{Li})$. This level is selected to avoid pump cavitation. It is monitored by the liquid level indicator LS102. The pump will neither start nor continue to run if the lithium drops below this level.

- high level: $22 \mathrm{~cm}(8.75 \mathrm{in})$ from the top of the tank; at this level, there are 245 liters ( 65 gal.) of lithium in the dump tank. If this level indicator is not illuminated, it indicates that a significant quantity ( 110 liter; more than $30 \%$ ) of the lithium inventory is not in the dump tank. If this situation arises, steps must be taken to investigate the cause.

- Pump Inlet

- single level: $6 \mathrm{~mm}$ (0.25 in), from bottom of pump suction pipe. This probe gives the first indication that lithium is rising up into the loop.

- Pump Outlet

- single level: $6 \mathrm{~mm}$ (0.25 in), from top of pump discharge pipe, and $29 \mathrm{~cm}$ (11.5 in) above pump discharge flange. This probe gives the first indication that the pump is full of lithium.

- Upstream of HV101

- lower level: $6 \mathrm{~mm}$ (0.25 in), from the bottom of the pipe. This probe gives the first indication that the loop piping is starting to fill with lithium.

- upper level: $6 \mathrm{~mm}$ (0.25 in), from the top of the pipe. This probe gives the first indication that the loop piping is almost full of lithium. 
- Surge Tank

- Low level: The low level indicator LS103 is set near the bottom of the surge tank. This indicator signals that the loop is filled and that lithium circulation can start.

- high level: The high level indicator LS104 is set $30 \mathrm{~cm}$ (12") from the bottom of the surge tank. The lithium level will normally be below this point. . During normal operation the lithium level is between those corresponding to the high and low level indicator.

- overflow level: The overflow level indicator LS105 is set at the very top of the surge tank. If lithium reaches this level, the loop will undergo an automatic, emergency shutdown.

\section{Acknowledgments}

The authors wish to thank Mr. David B. Chojnowski for his dedication and hard work in upgrading the ALEX facility. This work was supported by the US Department of Energy, Office of Fusion Energy, under Contract W-31-109-Eng-38.

\section{References}

[1] T. Q. Hua and Y. Gohar, "MHD Pressure Drops and Thermal Hydraulic Analysis for the ITER Breeding Blanket," Fusion Eng. Des. 27 (1995) 696-702.

[2] K. Natesan, C. B. Reed, and R. F. Mattas, "Assessment of Alkali Metal Coolants for the ITER Blanket," Fusion Eng. Des. 27 (1995) 457-466.

[3] C. B. Reed, K. Natesan, T. Q. Hua, I. R. Kirillov, I. V. Vitkovski, and A. M. Anisimov, "Summary Report for ITER Task - T19: MHD Pressure Drop and Heat Transfer Study for Liquid Metal Systems," ANL/FPP/TM-281, ITER/US/95/IV-BL-05, March 1995. 


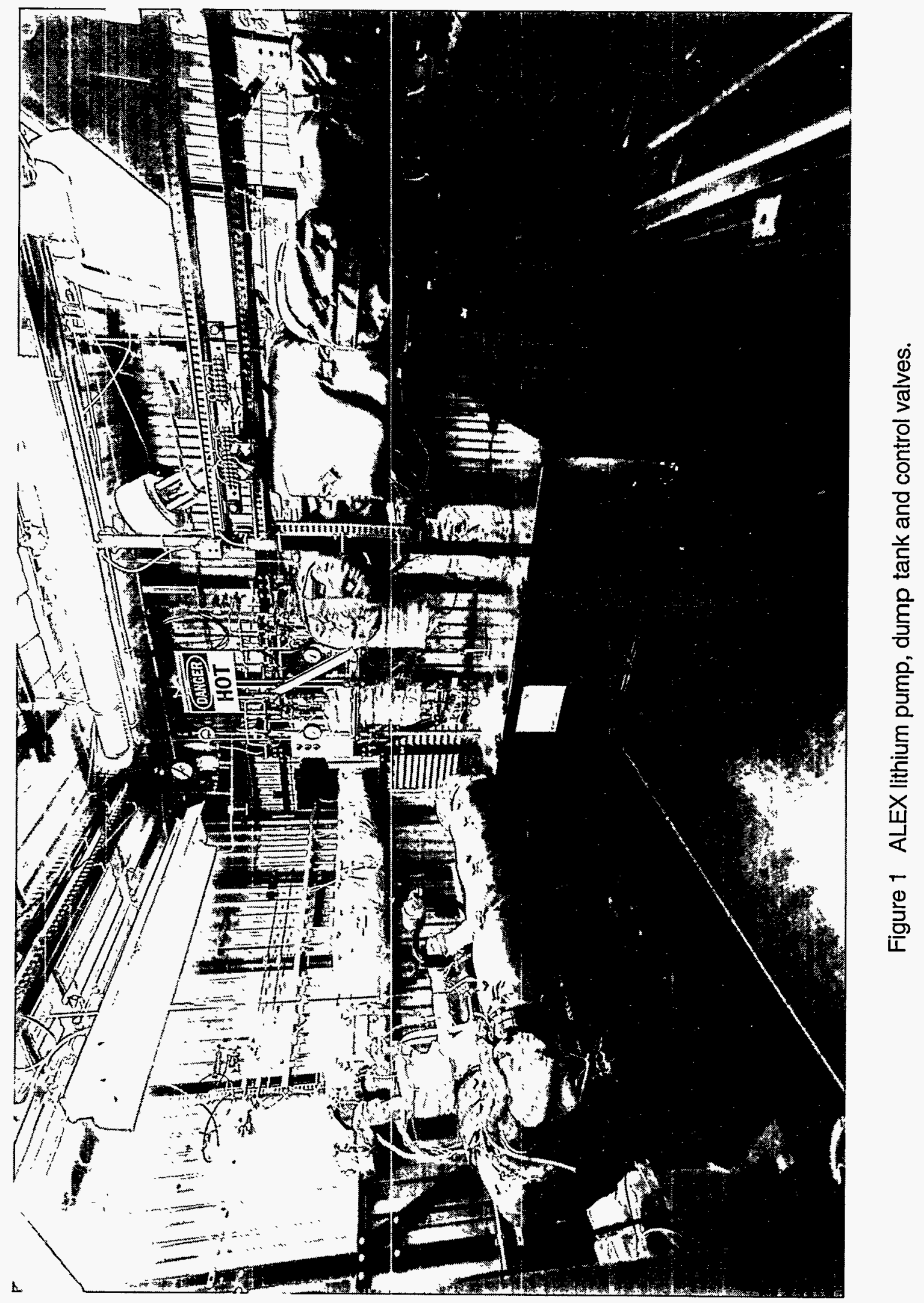




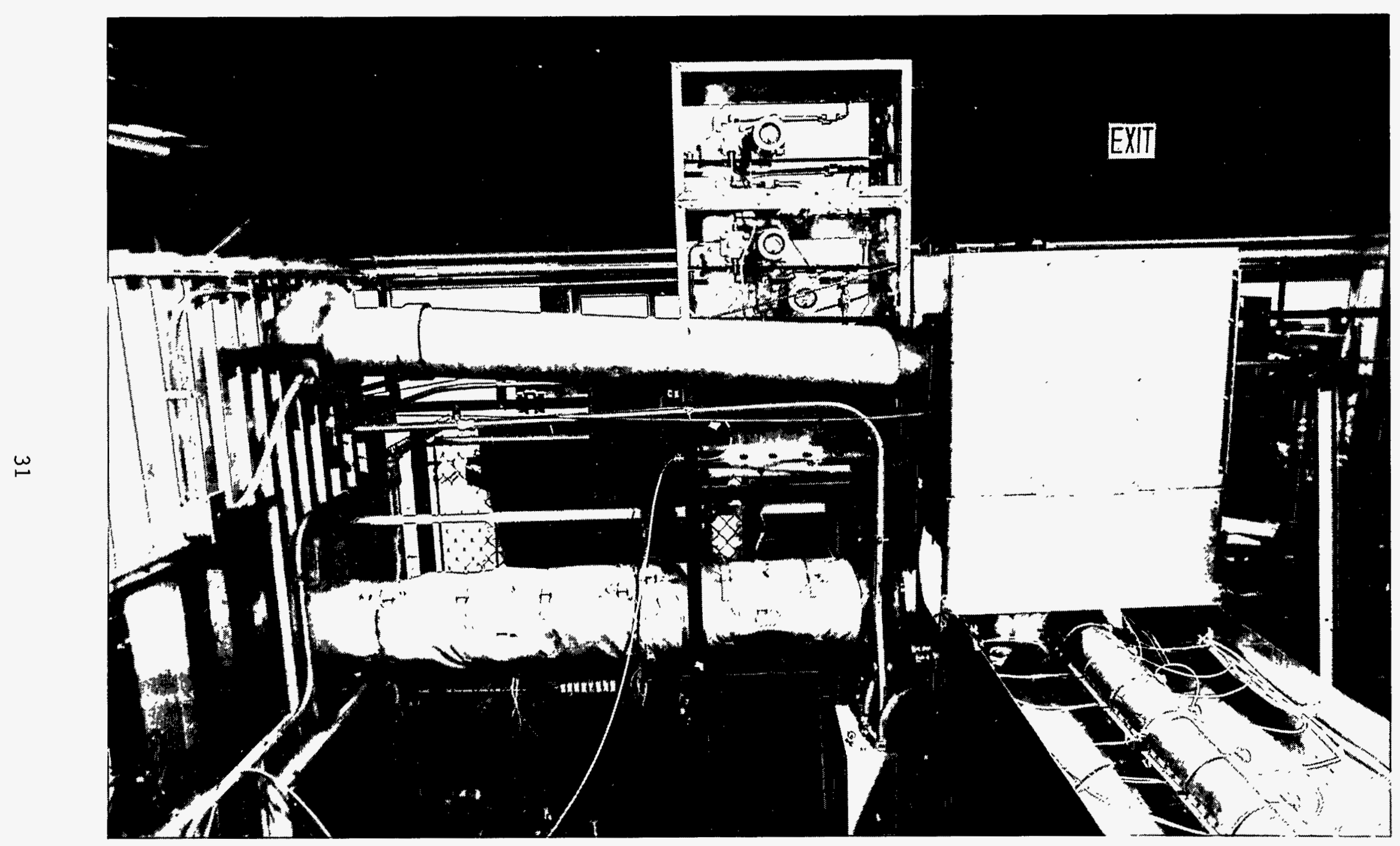

Figure 2 ALEX pressure measurement system. 




Figure 3 ALEX NaK-filled heat exchanger and containment. 


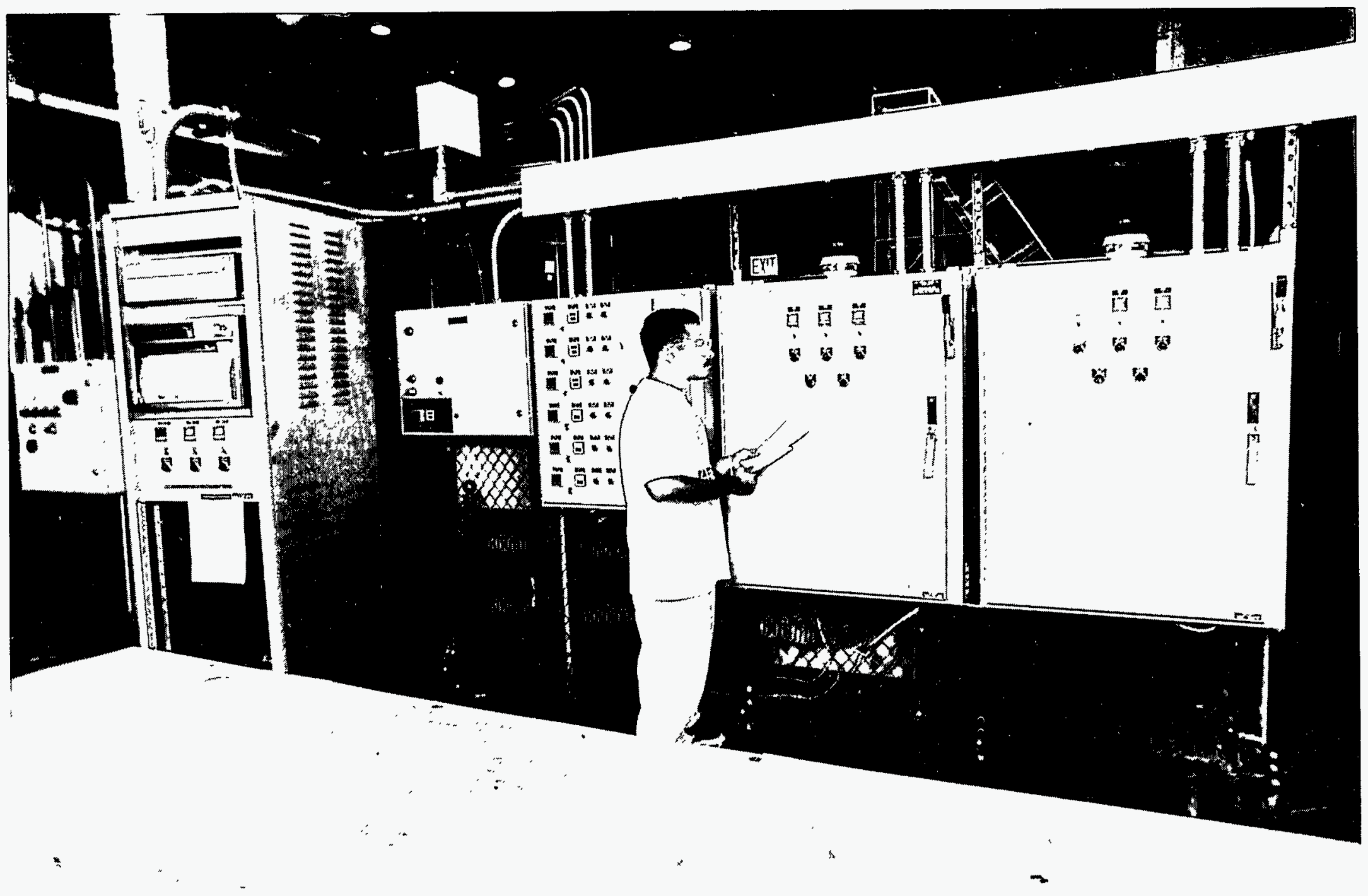

Figure 4 ALEX heater control cabinets. 


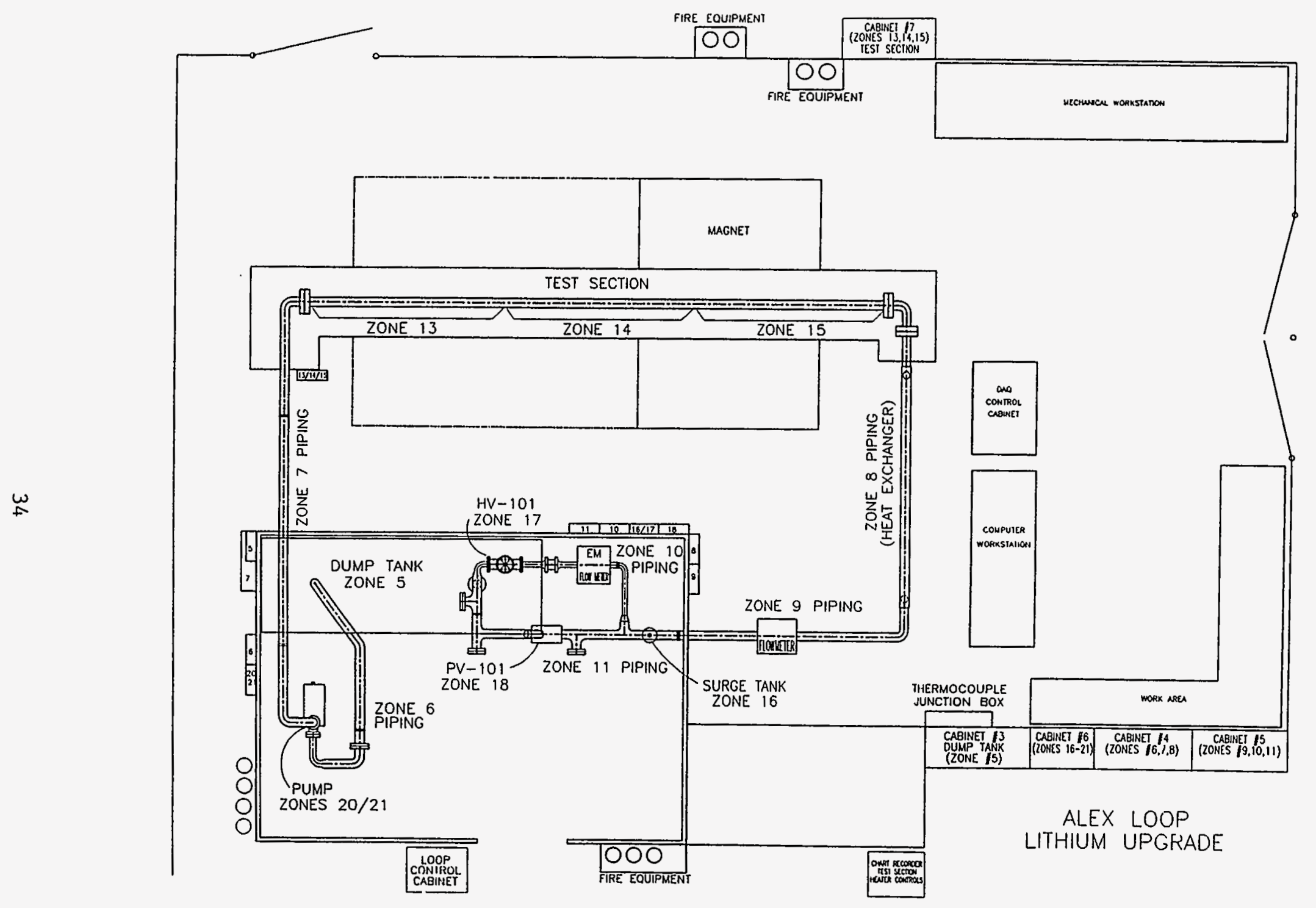

Figure 5 ALEX heating system zones. 
Figure 6 ALEX loop lithium upgrade piping and instrumentation drawing, 60553-0160-DD.



NOTE: SUPERSEDES DWG \#G0553-0136-DD 


\section{DISTRIBUTION LIST FOR ANL/FPP/TM-288}

Internal
H. Attaya
S. Bhattacharyya
M. Billone
J. Brooks
D. Ehst
Y. Gohar
R.C. Haglund
A. Hassanein

T. Hua

C. Johnson

T. Kassner

M. Lineberry

R. Mattas

M.E. Miller

J.R. Nasiatka

K. Natesan
J.H. Park

C.B. Reed (9)

Dale L. Smith

D.-K. Sze

FPP Files (5)

TIS Files (1)

\section{External}

DOE/OSTI for distribution per UC-424 (41)

Manager, Chicago Operations Office

ANL-E Libraries (2)

ANL-W Library

M. Abdou, University of California, Los Angeles

K. Abe, Tohoku University, Japan

C. Baker, University of California, San Diego

L. Barleon, Forschungszentrum Karlsruhe, Germany

S. Berk, U.S. Department of Energy

H. Bolt, Institute for Materials in Energy Systems - IWE, Germany

L. Bühler, Forschungszentrum Karlsruhe, Germany

R. Causey, Sandia National Laboratories, Livermore

M. Cohen, U.S. Department of Energy

W. Daenner, ITER JCT, Garching, Germany

J. Doggett, Lawrence Livermore National Laboratory

W. Gauster, ITER JCT, Garching, Germany

G. Goloubovitch, Efremov Institute, St. Petersburg, Russia

J. Hunter, Sandia National Laboratories, Albuquerque

T. James, University of California, San Diego

K. loki, ITER JCT, Garching, Germany

Y. Kato, Japan Atomic Energy Research Institute, Japan

I. Kirillov, Efremov Institute, St. Petersburg, Russia

O. Lielausis, Institute of Physics, Latvia

S. Malang, Forschungszentrum Karlsruhe, Germany

Y. Martynenko, Kurchatov Institute, Russia

K. McCarthy, Idaho National Engineering Laboratory

J. McWhirter, Idaho State University

K. Miya, University of Tokyo, Japan

K. Miyazaki, Osaka University, Japan

Y. Momozaki, Tokyo Institute of Technology, Japan

O. Motojima, National Institute for Fusion Science, Japan

U. Müller, Forschungszentrum Karlsruhe, Germany

E. Muraviev, ITER JCT, San Diego, California 

A. Ogorodnikov, Efremov Institute, St. Petersburg, Russia
R. Parker, ITER JCT, Garching, Germany
S. Piet, ITER JCT, San Diego, California
G. Preslitski, Efremov Institute, St. Petersburg, Russia
R. Price, U.S. Department of Energy
M. Seki, Japan Atomic Energy Research Institute, Japan
Y. Strebkov, RDIPE, Moscow, Russia
M. Tillack, University of California, San Diego
J. Vetter, Forschungszentrum Karlsruhe, Germany
G. Vieider, ITER JCT, Garching, Germany
F.W. Wiffen, U.S. Department of Energy
K. Wilson, Sandia National Laboratories, Livermore
Bibliothek, Max-Planck-Institute fur Plasmaphysik, Germany
C.E.A. Library, Fontenay-aux-Roses, France
Librarian, Culham Laboratory, England
Thermonuclear Library, Japan Atomic Energy Research Institute, Japan 